Supporting Information

\title{
Double-Walled Metal-Organic Framework with Regulable Pore Environments for Efficient Removal of Radioactive Cesium Cations
}

Dan Tian, ${ }^{\dagger}$ Tian-Tian $\mathrm{Wu},{ }^{\dagger}$ Yan-Qing Liu, ${ }^{\dagger} \mathrm{Na} \mathrm{Li}^{\ddagger *}$

${ }^{\dagger}$ College of Materials Science and Engineering, Co-Innovation Center of Efficient Processing and Utilization of Forest Resources, Nanjing Forestry University, Nanjing 210037, China

${ }^{\ddagger}$ School of Materials Science and Engineering, Tianjin Key Laboratory of Metal and Molecule-Based Material Chemistry, Nankai University, Tianjin 300350, China

*E-mail: lina@nankai.edu.cn 


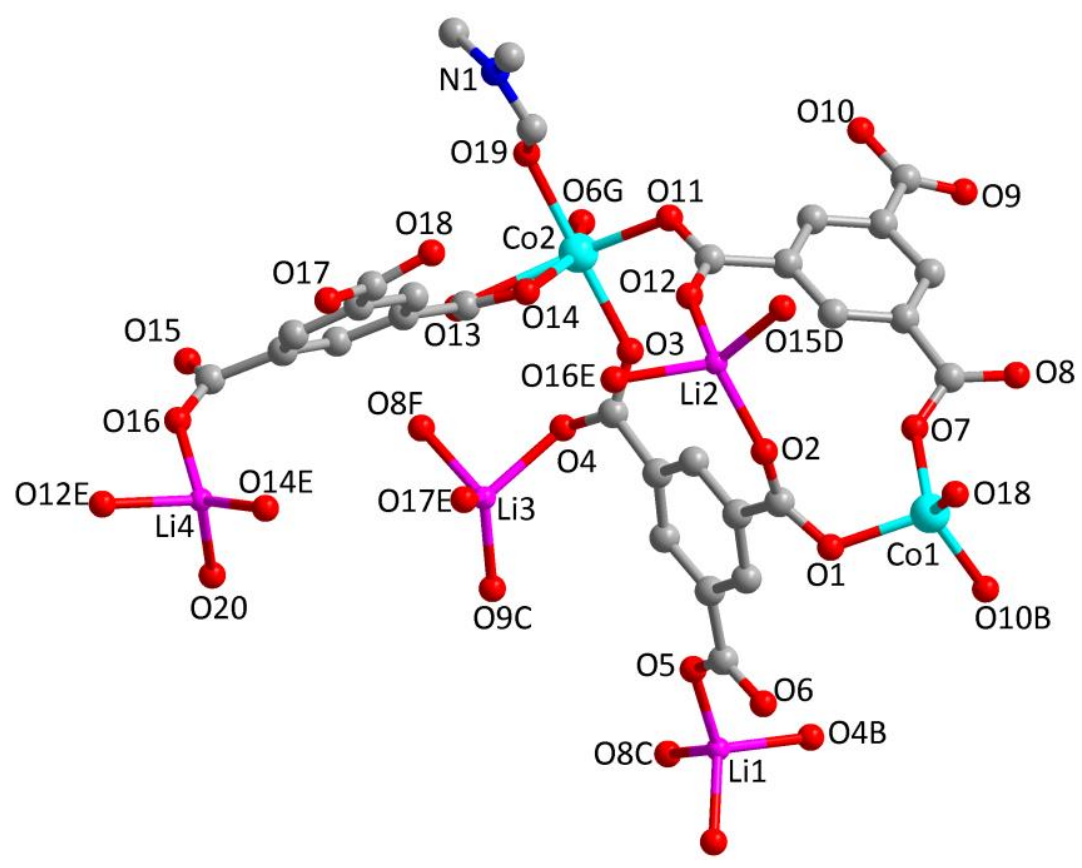

Fig. S1 Coordination environments of $\mathrm{Co}^{2+}$ and $\mathrm{Li}^{+}$ions in compound $\mathbf{1}$. Symmetry codes: A: 3/2-x, 1/2-y, 3/2-z; B: -3/4+x, 3/4-y, 1/4+z; C: -3/4+x, 3/4-y, -3/4-z; D: x, y, 1+z; E: 3/2-x, 1/2-y, 1/2-z; F: x, y, -1+z; G: 3/4-x, 3/4+y, -1/4+z. 

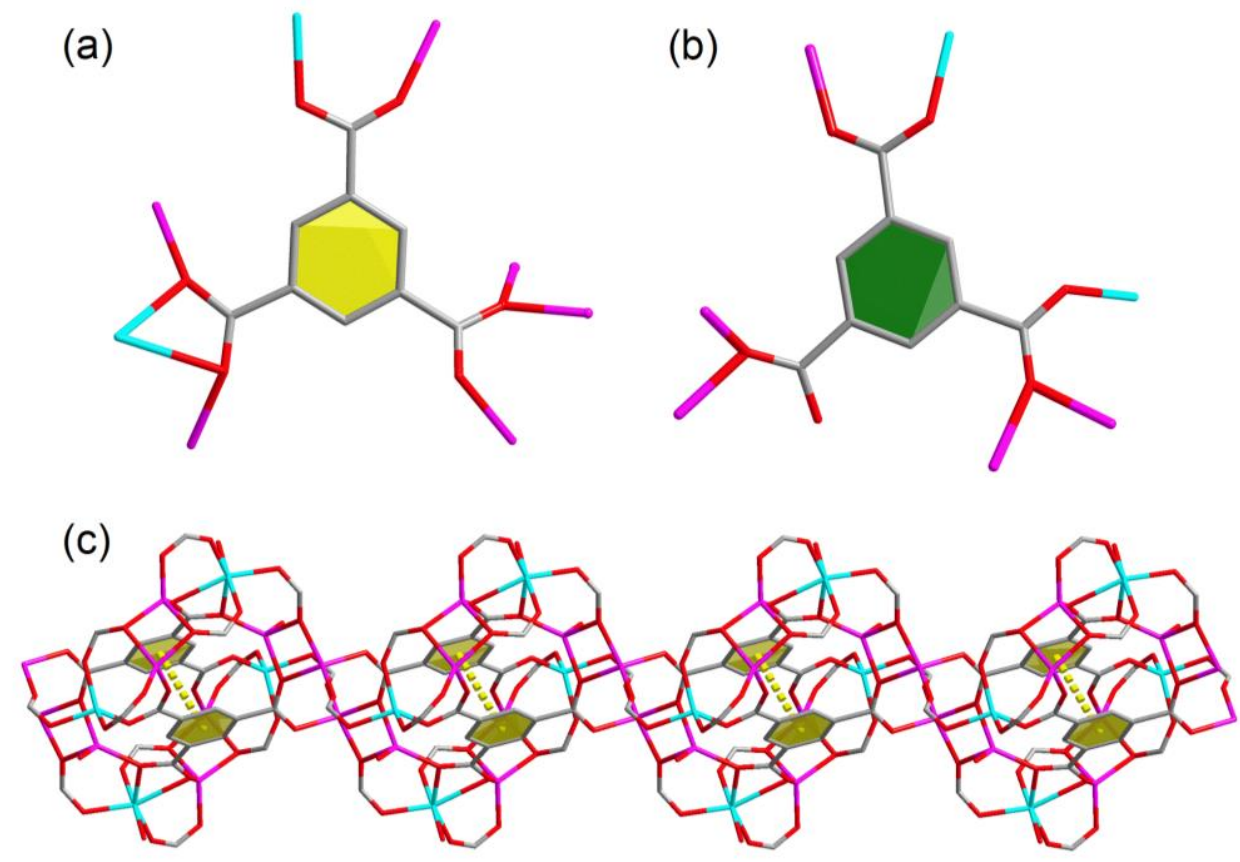

Fig. S2 (a) Coordination mode of $\mathrm{L}_{\mathrm{a}}$ ligand. (b) Coordination mode of $\mathrm{L}_{\mathrm{b}}$ ligand in compound $\mathbf{1}$. (c) The chain constructed by double-walled units connecting with each other.

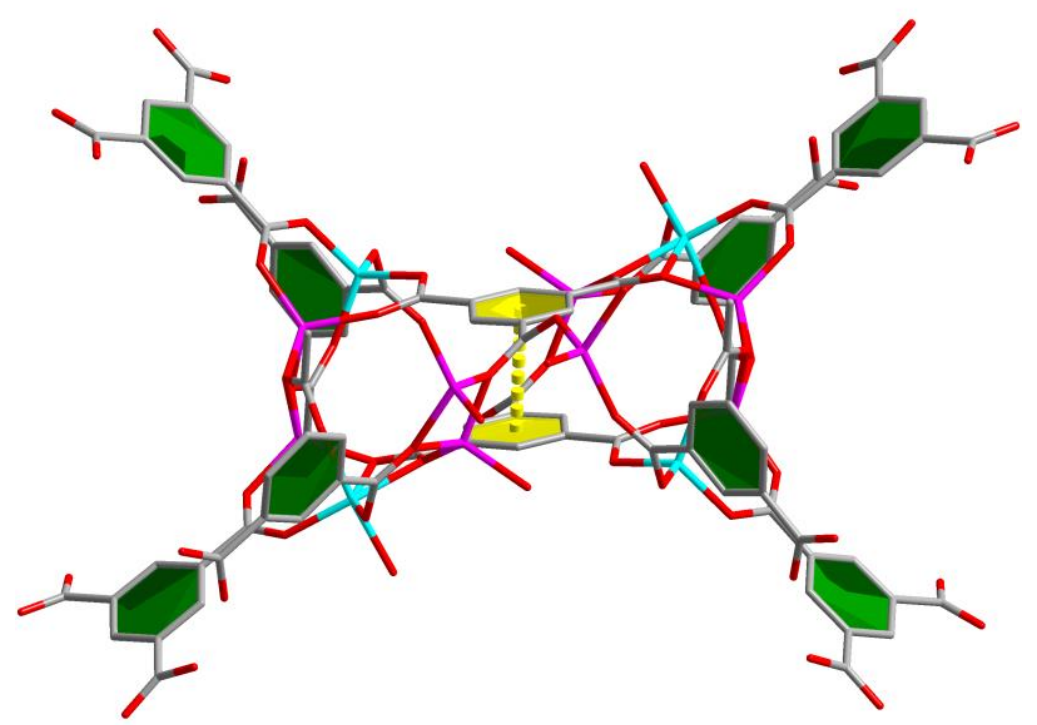

Fig. S3 The double-walled chain linked by $L_{b}$ ligands viewed in the direction of $c$. 


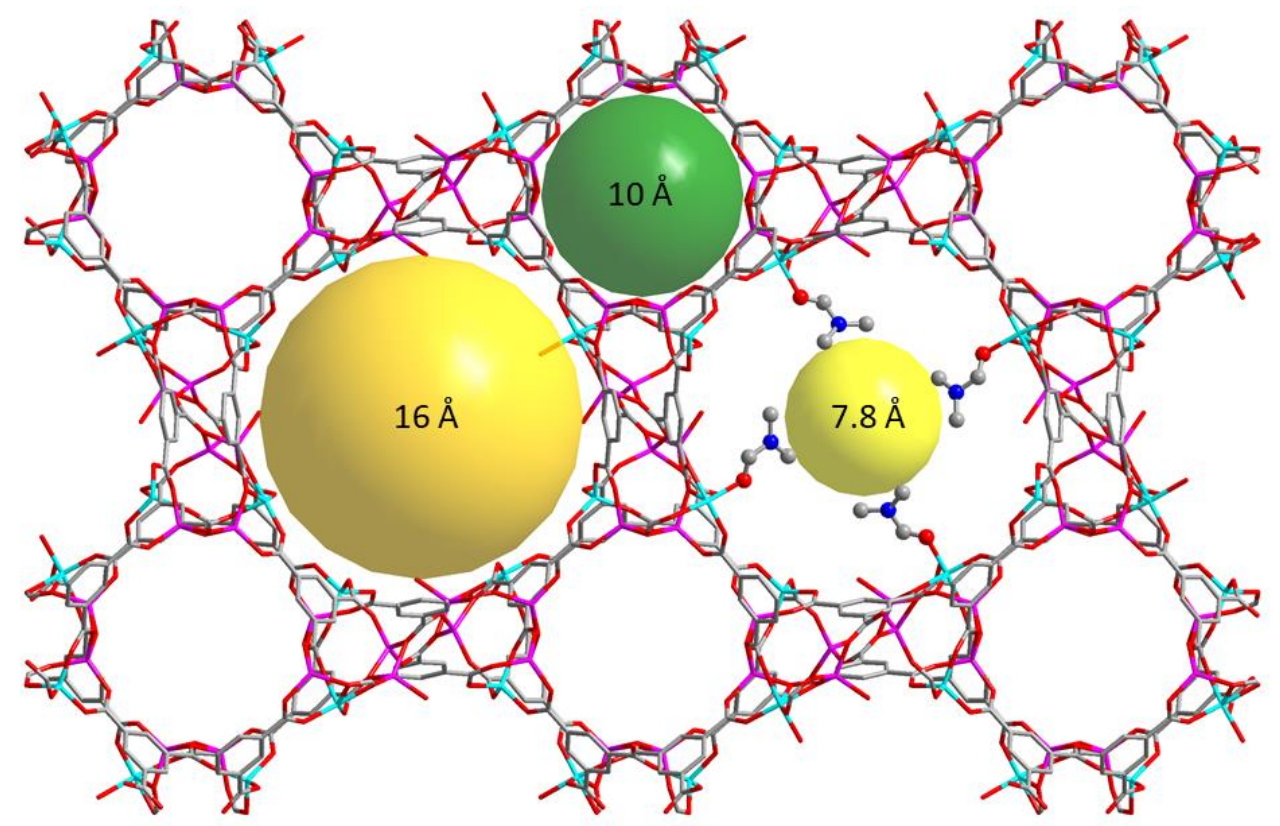

Fig. S4 The large and small channels enriched by four double-walled chains and Lb ligands. 


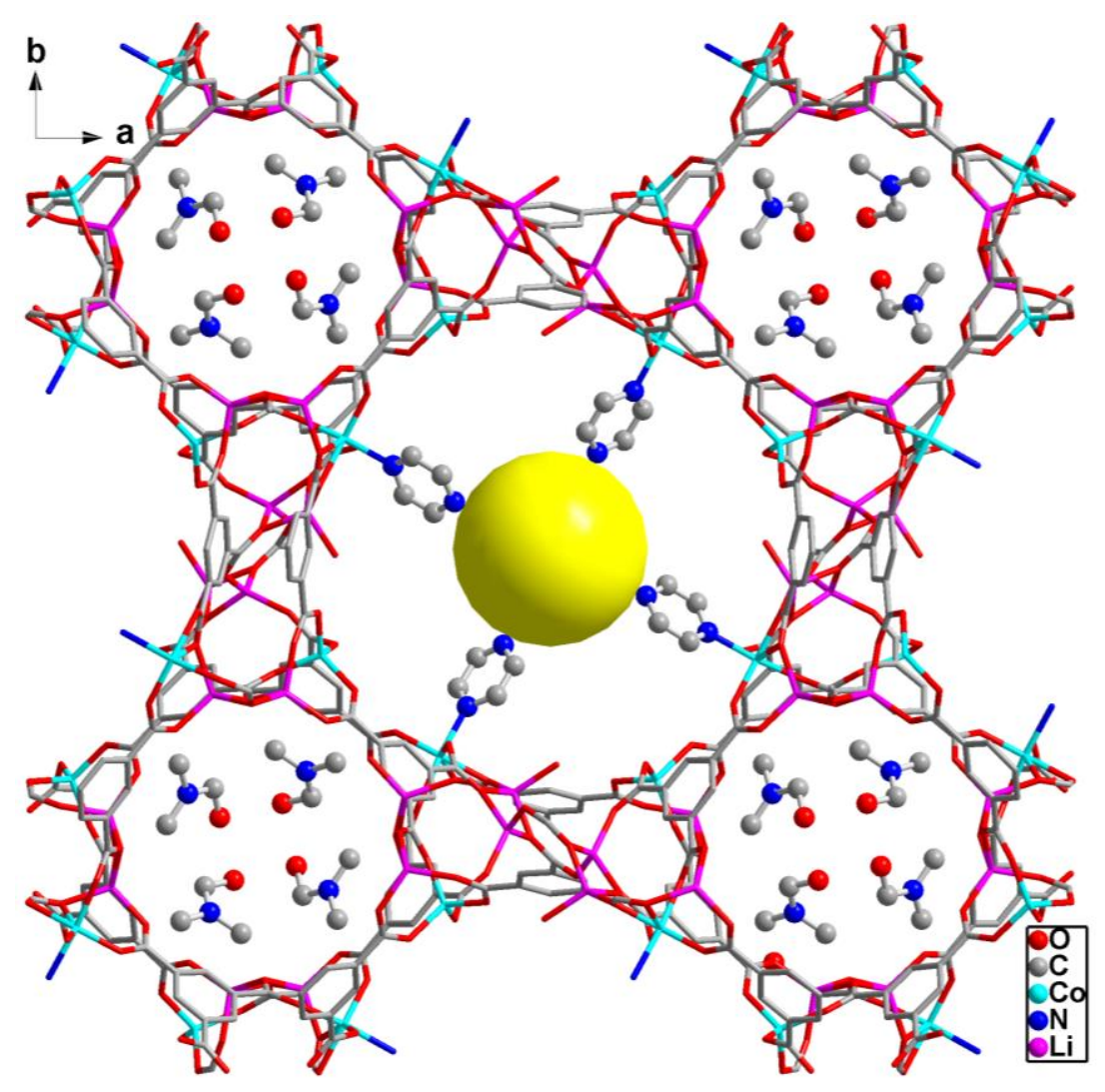

Fig. S5 The 3D porous structure of 2 viewed on the direction of $c$. The pore channels with pyrazine molecules on the pore walls. 


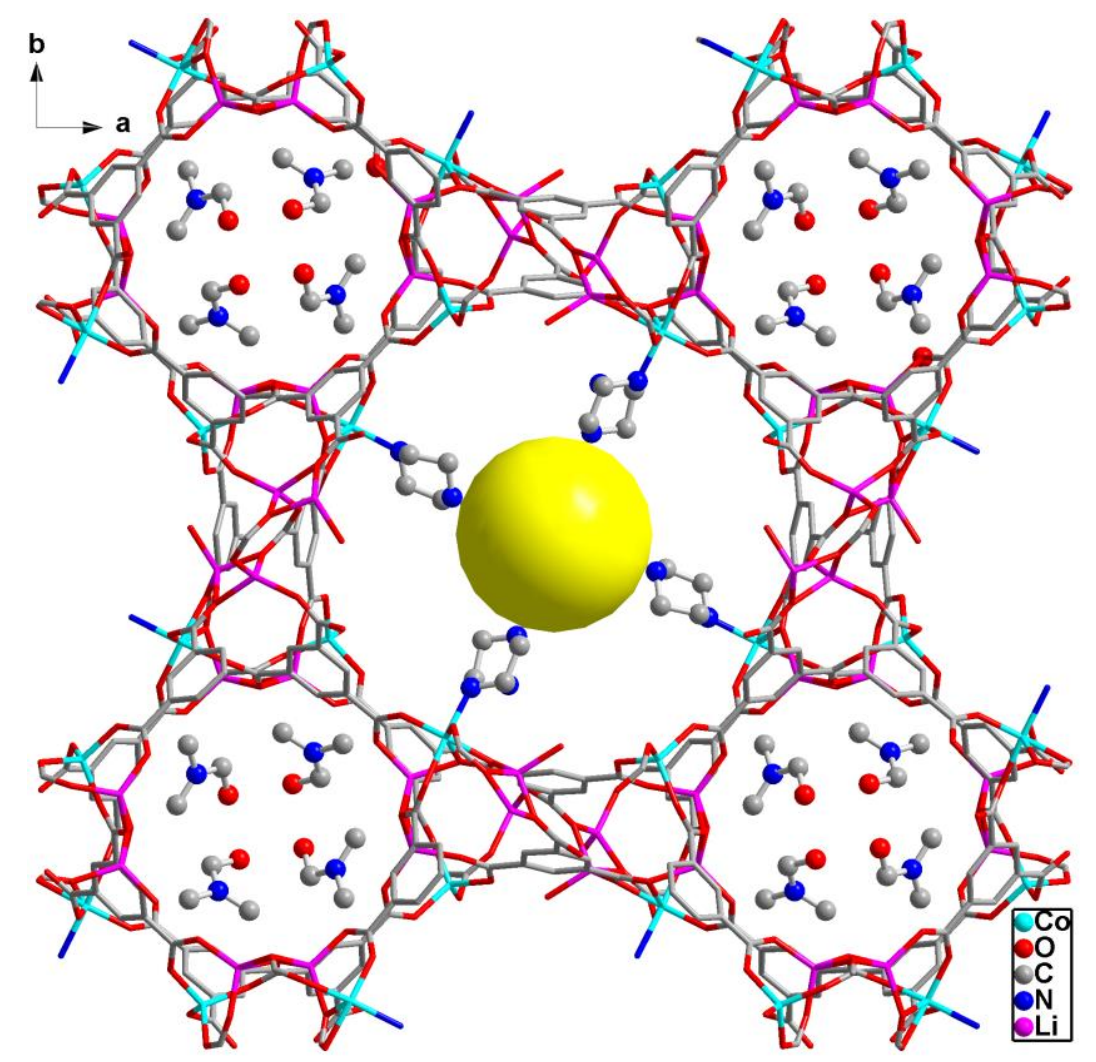

Fig. S6 The 3D porous structure of $\mathbf{3}$ viewed on the direction of $c$. The pore channels with piperazine molecules on the pore walls. 


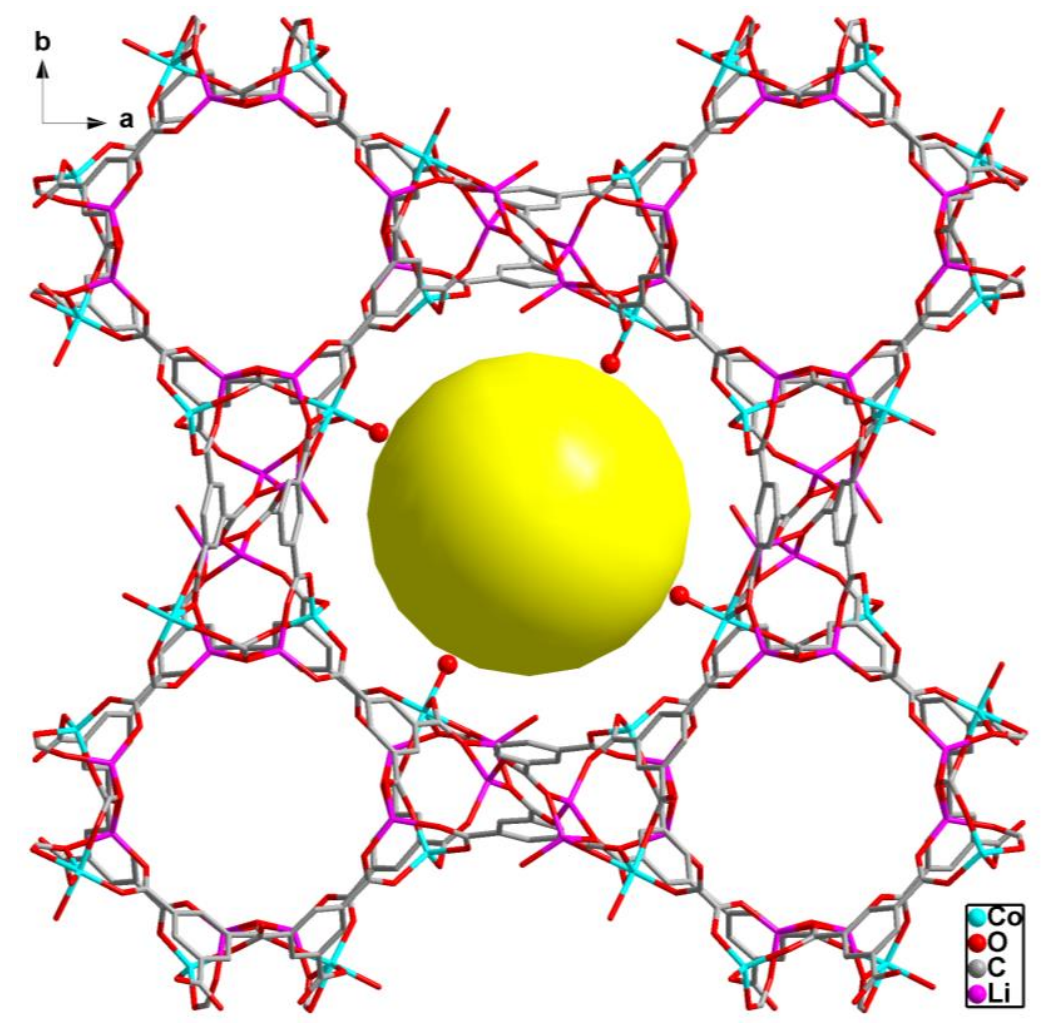

Fig. S7 The 3D porous structure of $\mathbf{4}$ viewed in the direction of $c$. The pore channels with coordinated water molecules on the pore walls. 


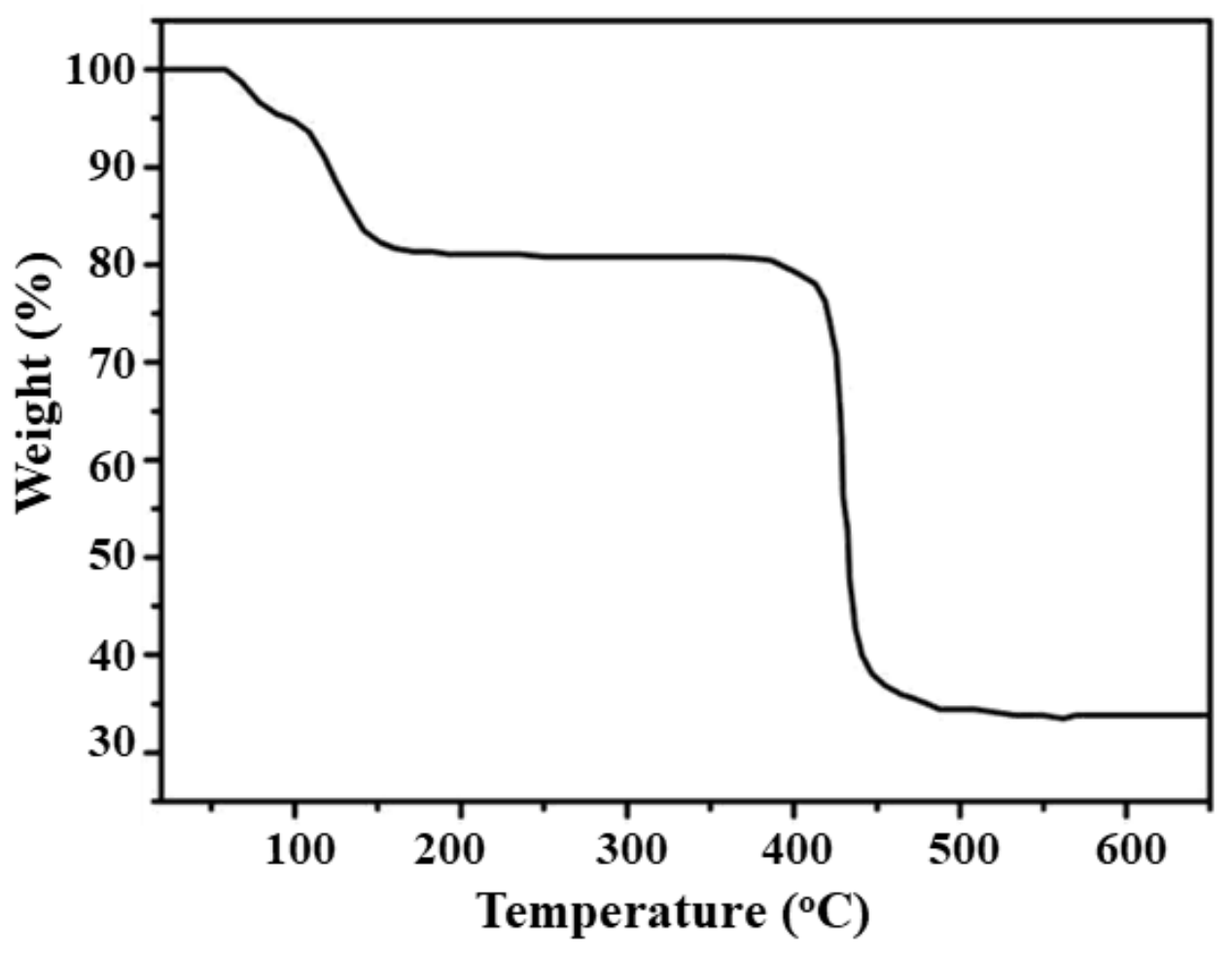

Fig. S8 Thermagravimetric profile for $\mathbf{1}$. 


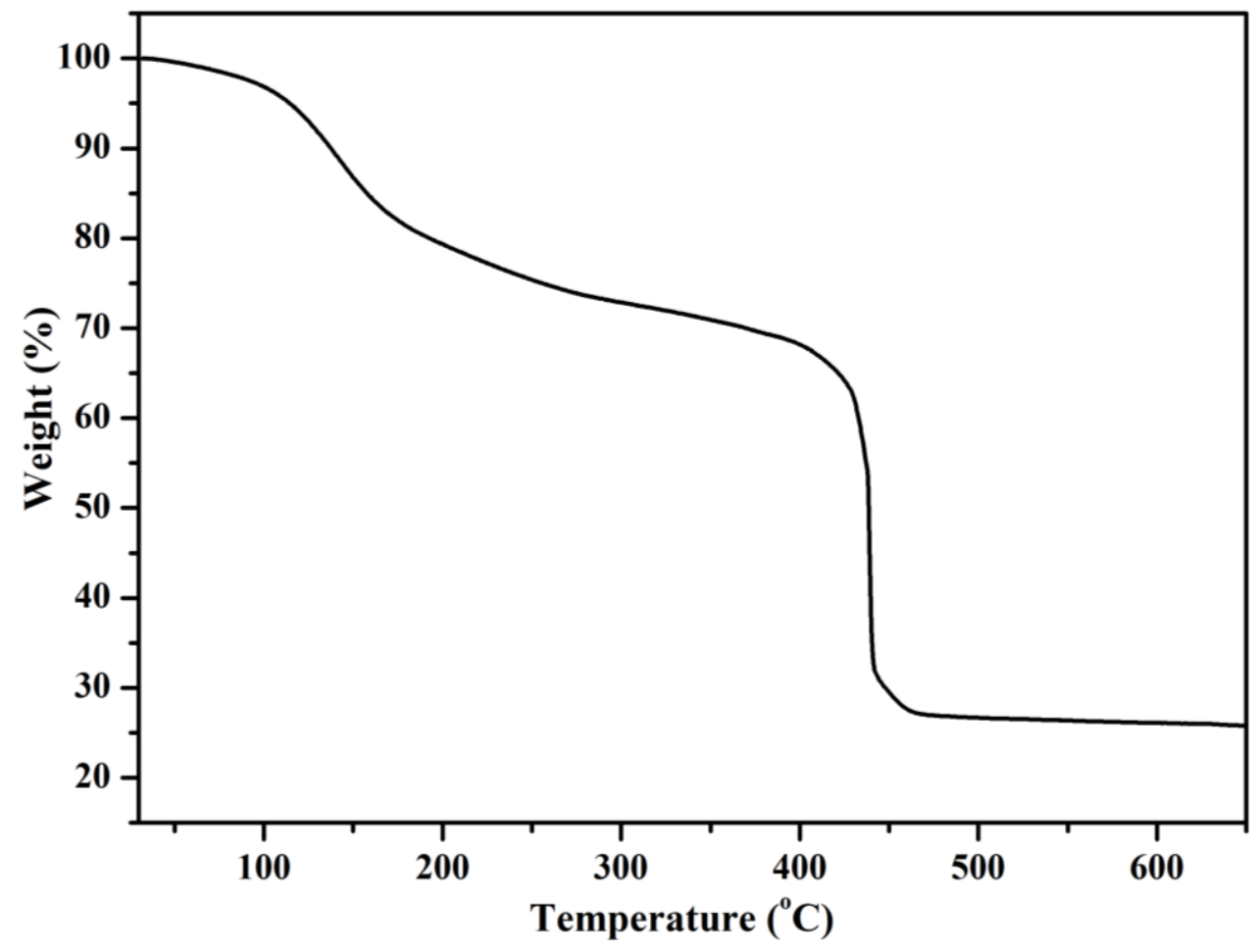

Fig. S9 Thermagravimetric profile for 2 . 


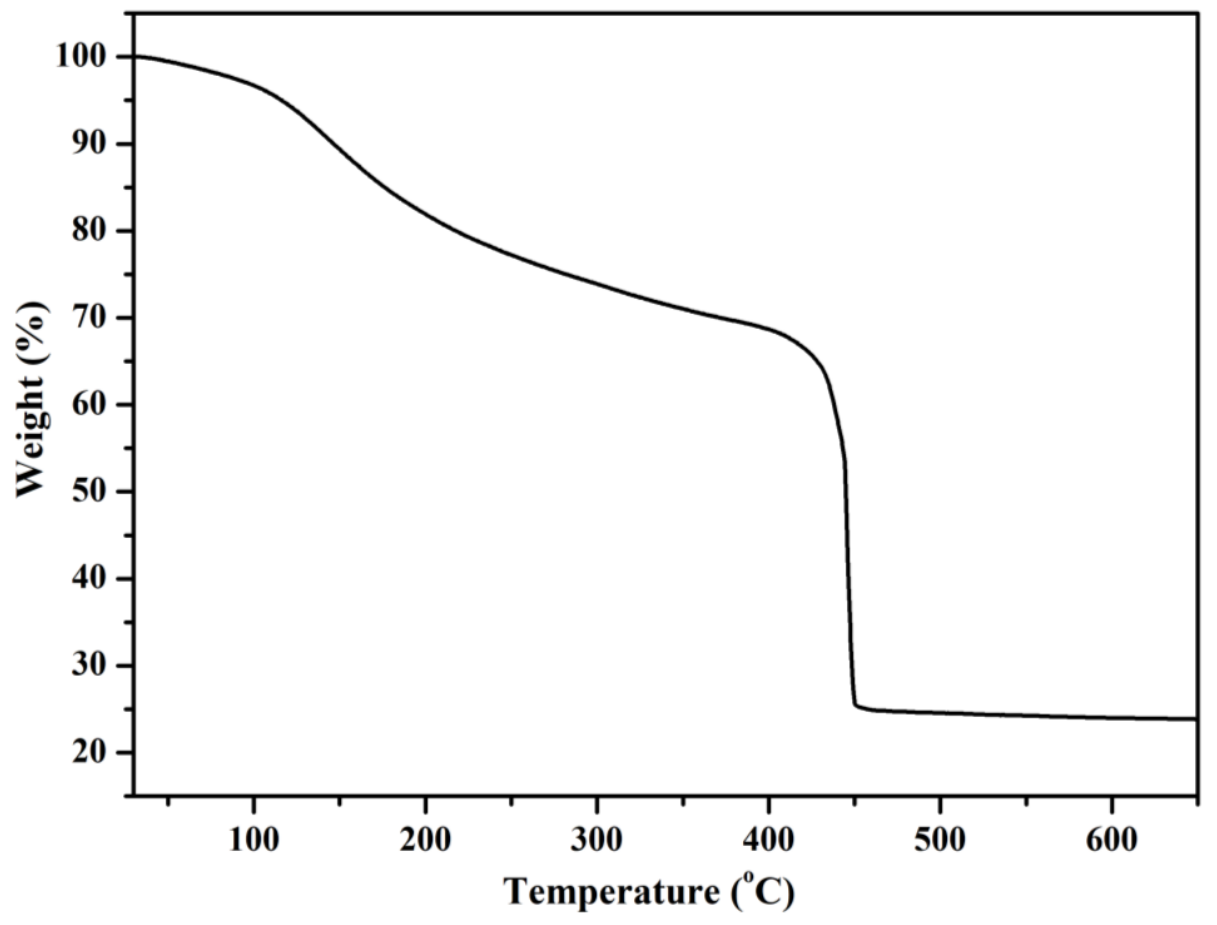

Fig. S10 Thermagravimetric profile for 3 . 


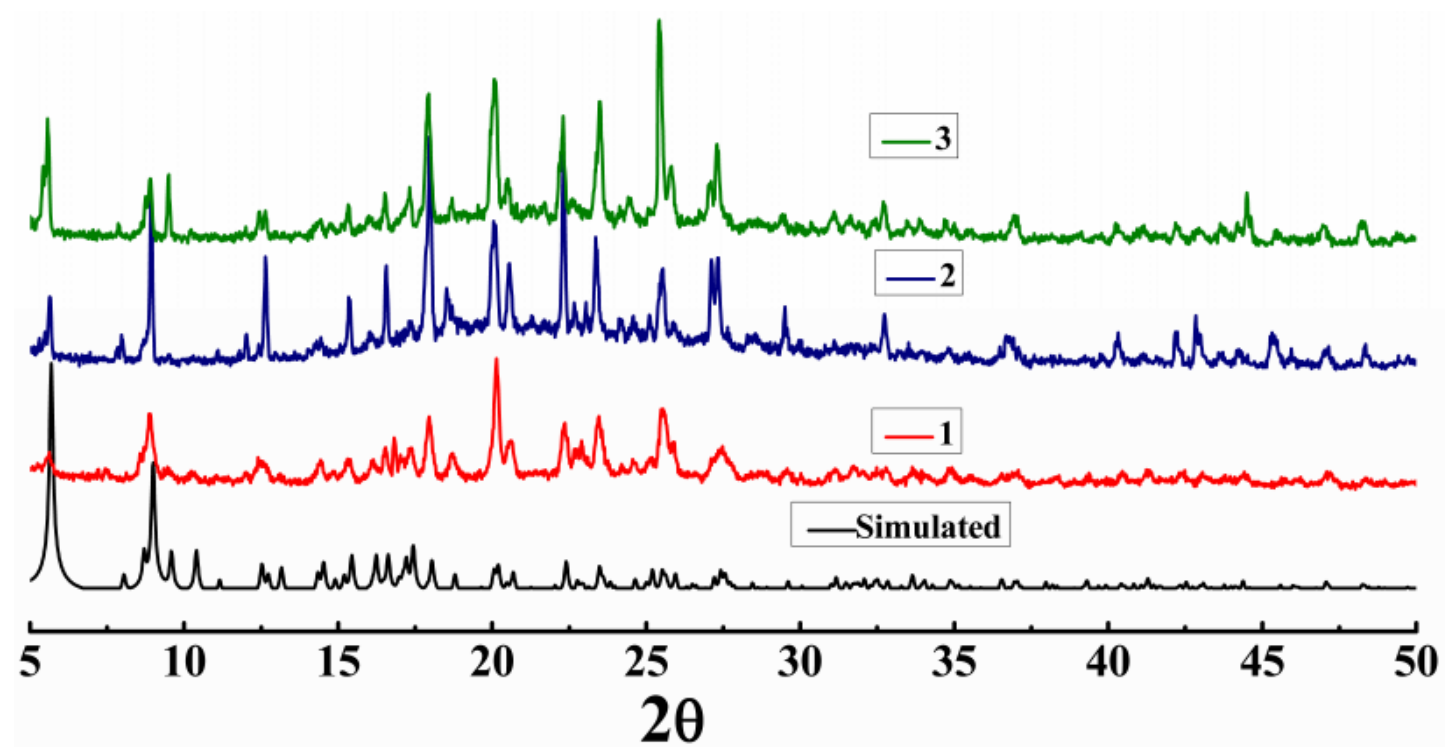

Fig. S11 Simulated PXRD pattern of 1 and experimental PXRD patterns of the as-synthesized 1-3. 


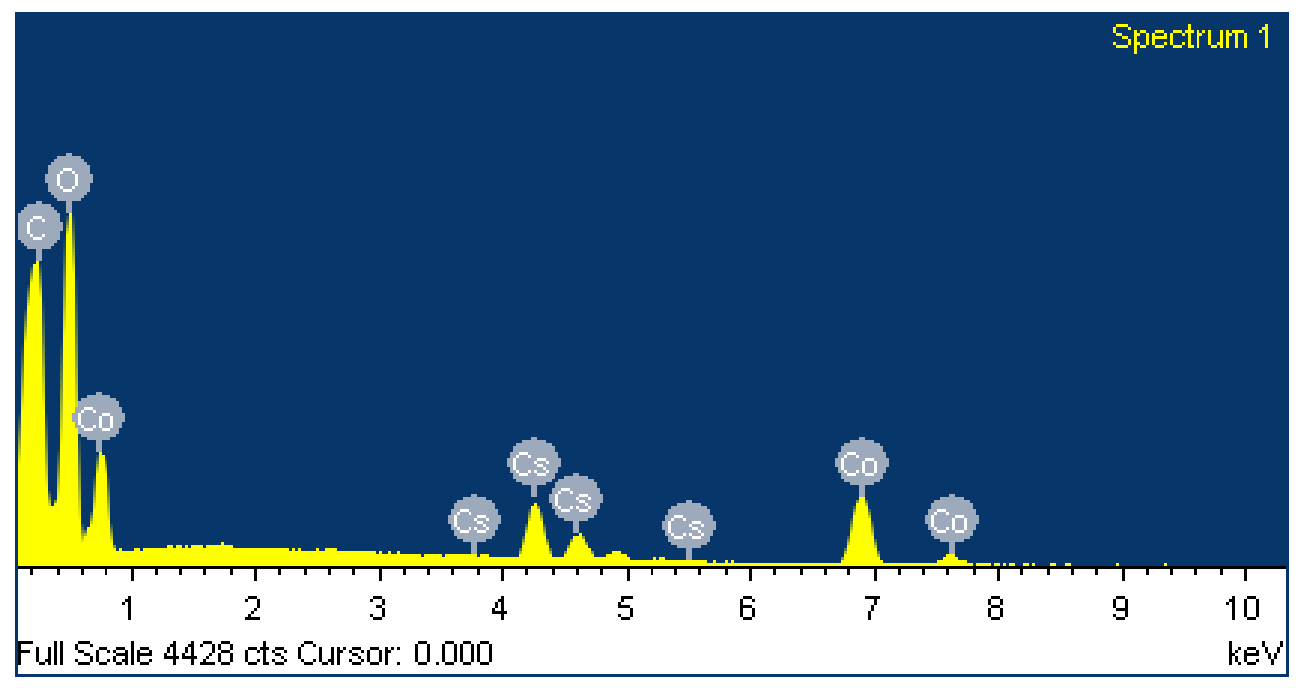

Fig. S12 EDS spectra of compound 2. 

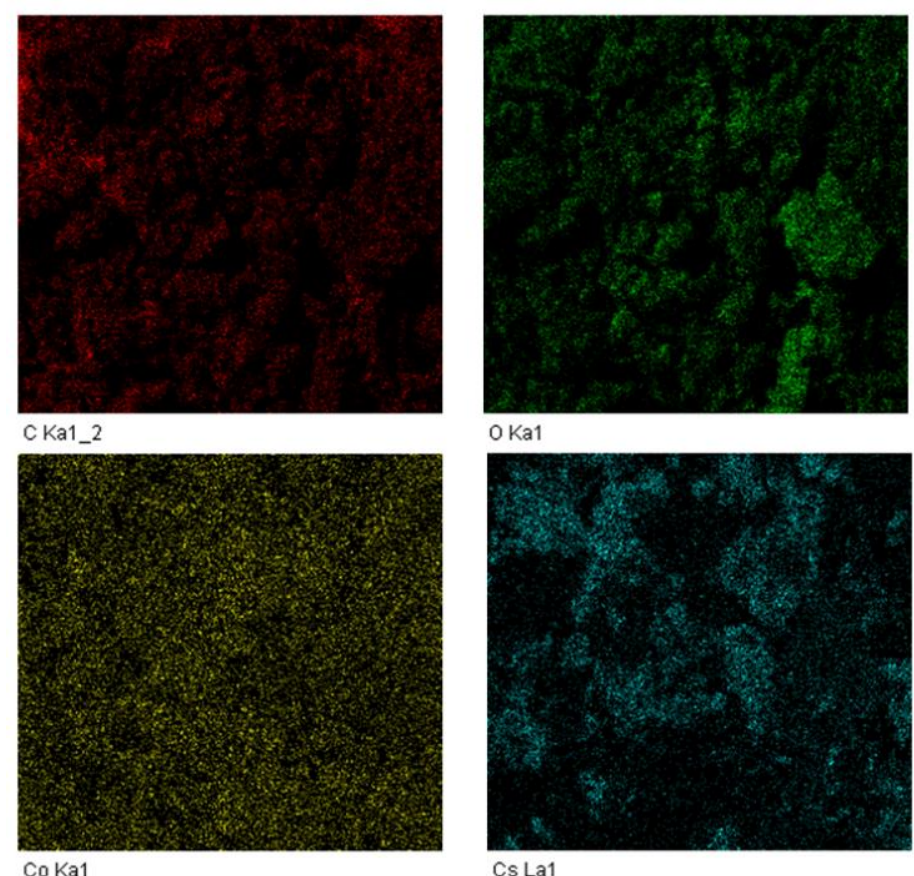

Cs La1

Fig. S13 EDS elemental mapping of Co, Cs, O and $\mathrm{C}$ elements for compound 2. 

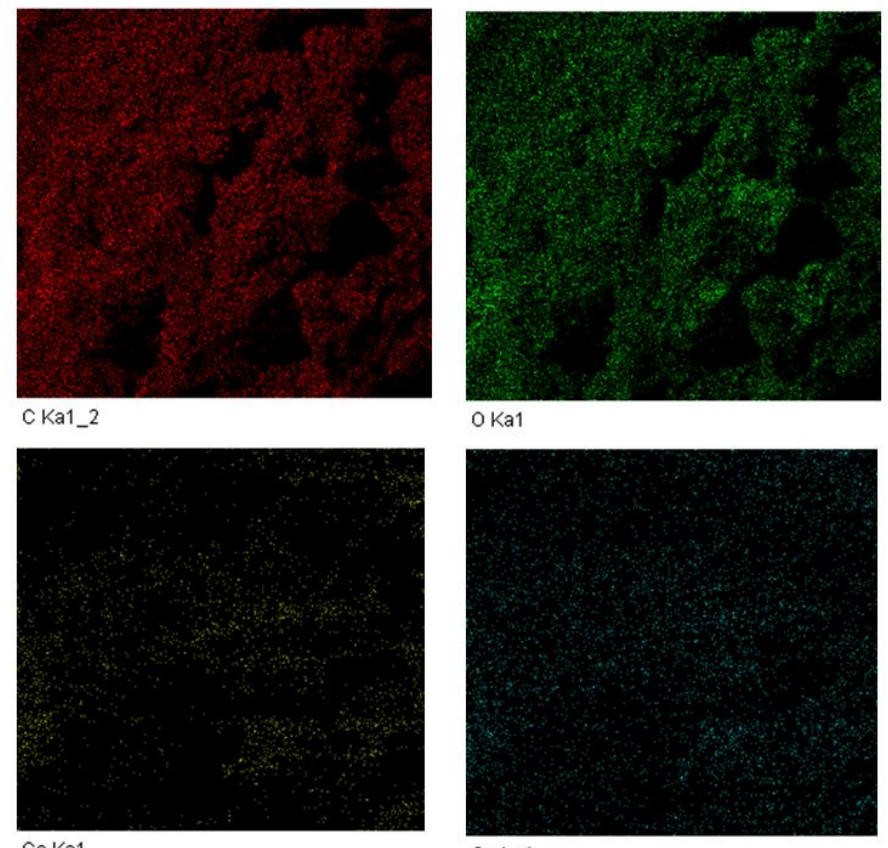

OKa1

Co Ka1

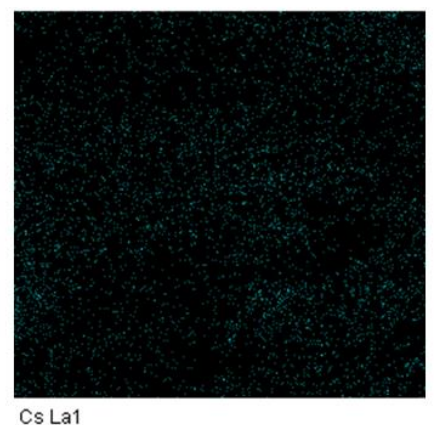

Fig. S14 EDS elemental mapping of Co, Cs, O and $\mathrm{C}$ elements for compound $\mathbf{3}$. 

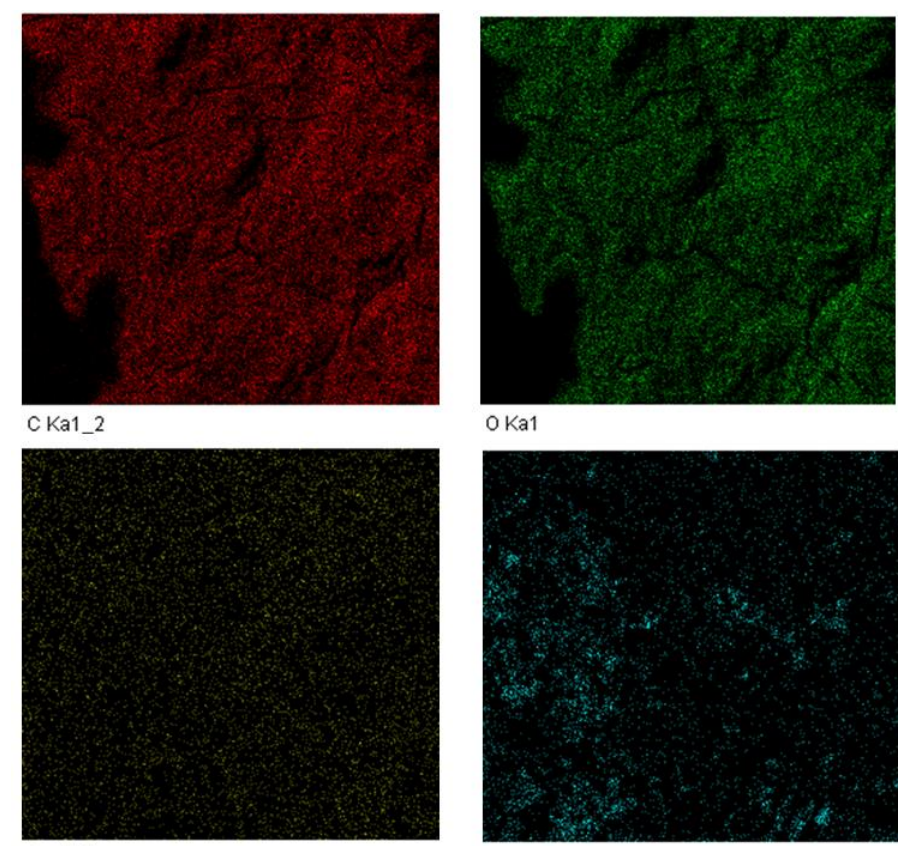

O Ka1

Co Ka1

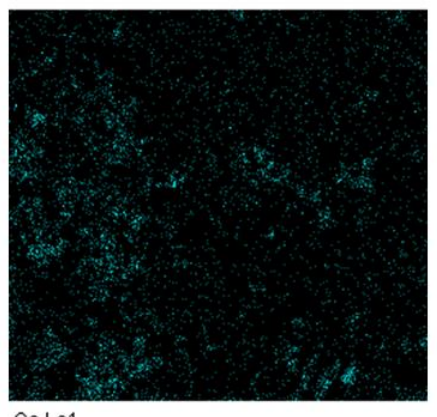

Fig. S15 EDS elemental mapping of $\mathrm{Co}, \mathrm{Cs}, \mathrm{O}$ and $\mathrm{C}$ elements for compound 4. 


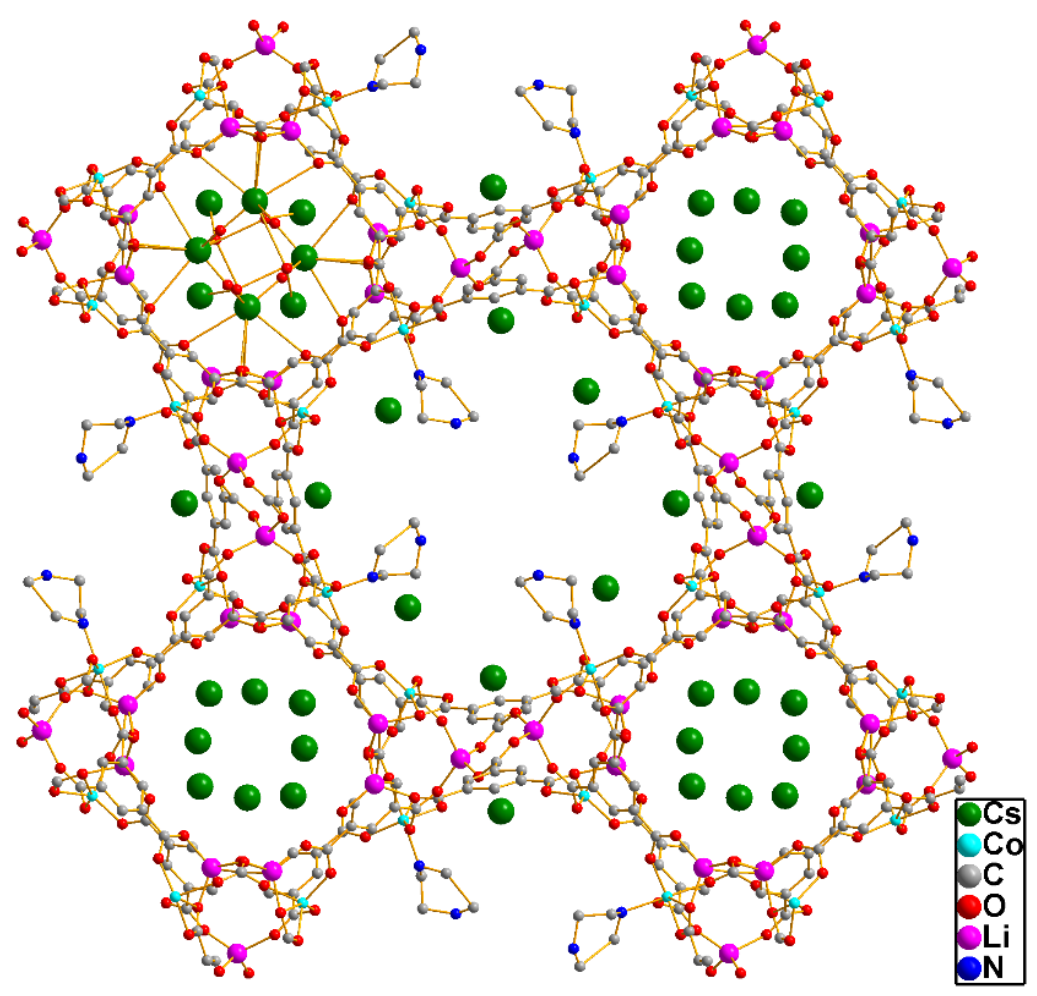

Fig. S16 The structure of $\mathbf{3} @ \mathrm{Cs}$ and the coordination environment of $\mathrm{Cs}^{+}$ ions in the framework. 


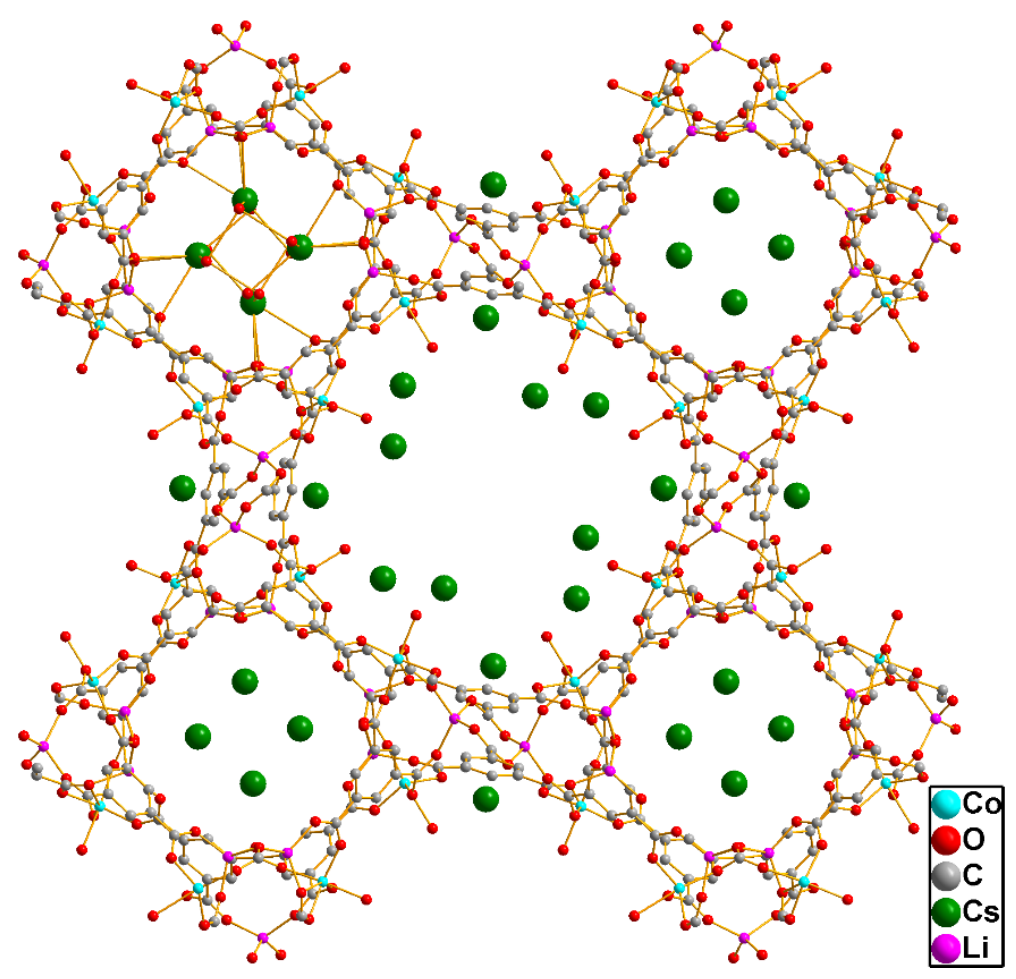

Fig. S17 The structure of $4 @ \mathrm{Cs}$ and the coordination environment of $\mathrm{Cs}^{+}$ ions in the framework. 
Table S1 Comparison of adsorption capacities of various adsorbents for $\mathrm{Cs}^{+}$adsorption.

\begin{tabular}{|l|c|l|}
\hline Type of adsorbents & Adsorption capacity $\left(\mathrm{mg} \mathrm{g}^{-1}\right)$ & References \\
\hline MIL-101-SO ${ }_{3} \mathrm{H}$ & 453 & 17 \\
\hline $\begin{array}{l}\text { uranyl organic } \\
\text { framework }\end{array}$ & 432 & 52 \\
\hline Compound 1 & 224.8 & This work \\
\hline GO/Co-MOF & 168.79 & 3 \\
\hline KNiFC & 153 & 5 \\
\hline Prussian blue-coated & 96.00 & 53 \\
magnetic nanoparticles & 80.3 & 54 \\
\hline Nd-BTC & 86 & 7 \\
\hline Ethylamine-modified & & 5 \\
montmorillonite & & 5 \\
\hline
\end{tabular}

